\title{
Comparison of Personas Between Two Academic Libraries
}

Holt Zaugg

Brigham Young University, holt_zaugg@byu.edu

Donna Harp Ziegenfuss

University of Utah, donna.ziegenfuss@utah.edu

Follow this and additional works at: https://scholarsarchive.byu.edu/facpub

Part of the Library and Information Science Commons

\section{Original Publication Citation}

Zaugg, H. \& Ziegenfuss, D. H. (2018). Comparison of personas between two academic libraries, Performance Measurement and Metrics, 19(3), 142-152.

\section{BYU ScholarsArchive Citation}

Zaugg, Holt and Ziegenfuss, Donna Harp, "Comparison of Personas Between Two Academic Libraries" (2018). Faculty Publications. 2722.

https://scholarsarchive.byu.edu/facpub/2722

This Peer-Reviewed Article is brought to you for free and open access by BYU ScholarsArchive. It has been accepted for inclusion in Faculty Publications by an authorized administrator of BYU ScholarsArchive. For more information, please contact ellen_amatangelo@byu.edu. 


\section{Comparison of Personas Between Two Academic Libraries}

Holt Zaugg

Assessment Librarian

Harold B. Lee Library

Brigham Young University

Provo, Utah, United States of America

Email: holt_zaugg@byu.edu

Donna Harp Ziegenfuss

Associate Librarian, Graduate \& Undergraduate Services

J. Willard Marriott Library

University of Utah

Salt Lake City, Utah, United States of America

Email: donna.ziegenfuss@utah.edu 


\begin{abstract}
Purpose: A persona describes a group of library patrons as a single person to better identify and describe user patterns and needs. Identifying personas in academic libraries can assist in library planning by focusing on patrons. Initially personas were thought to be unique to each library; additional insights led the researchers to rethink this assertion. This article seeks to determine if personas, developed in one library, are unique or more universal than previously thought.
\end{abstract}

Design/methodology/approach: In this study, 903 surveys were completed across two institutions asking library patrons to identify use patterns within each library. Mean score responses were analyzed using an ANOVA, principal component analysis (PCA), and RapidMiner technology. All analyses were used to identify personas with common interests and places personas in groups or neighborhoods.

Findings: The findings provide evidence for the universality of academic library personas. However, differences occur in how the personas are grouped and use different library services and resources.

Originality/value: Personas allow librarians to view patrons in a more personal way as they connect personas to specific library spaces. While the personas appear to be universal, their interactions with each other depends on specific library amenities. 


\section{Introduction}

An increasing desire to meet patron needs has resulted in librarians exploring new approaches to plan for and develop library services and resources. Traditional metrics (e.g., gate counts) no longer tell the full story of how academic libraries are being used. Large-scale library-assessment instruments (e.g., LibQUAL ${ }^{+}$, Ithaka survey) illuminate emerging trends as libraries adapt to patron use patterns. Additionally, libraries are also using local library assessments to better understand patron needs (Hiller, 2001; Roberts and Weaver, 2006). However, Hiller (2001) contends that we must make sure that the data we collect answers the questions we want to ask. He emphasizes the need to focus on answering questions related to local needs, as well as collecting data to benchmark against other similar institutions.

\section{Literature Review}

A new approach for uncovering the needs of local library users is to develop and use personas. Borrowed from marketing and design, personas consolidate use patterns and needs of a group of people into a single description (Guenther, 2006; McKay, 2010; Olsen, 2004; Pruitt \& Grudin, 2003). Instead of trying to think about individual group members, planners use the single persona to better plan for patron needs.

Once developed, personas are used in a variety of situations, including changes to library services (Al-Shboul \& Abrizah, 2014; Cunningham, 2005; Fourie \& Fourie, 2014; Olsen, 2004), developing smart-space technology (Bilandzic \& Foth, 2013), changing website design (Guenther, 2006), training employees (Idoughi, Seffah, \& Kolski, 2012), and improving library chat services (Tempelman-Kluit \& Pearce, 2014). Personas become a new way to identify patron needs and examine library services.

Methods for identifying, developing, and describing personas include surveys, observations, ethnographies, interviews, focus groups, and existing records (Blomquist \& Arvola, 2002; Cunningham, 2005; Guenther, 2006; Tempelman-Kluit \& Pearce, 2014). The persona descriptions may be brief portrayals of each patron group or they can be complex profiles that include artificial profile pictures and background information created by the persona designer.

The final step is to validate the personas found within the institution and to determine the total patron population percentage that each persona represents (Mulder \& Yaar, 2007). In the validation step, the persona designer creates use statements connected to each persona and asks a random sample of library patrons to indicate which use pattern statement best describes how they use the library. In this way, persona developers are able to determine if the persona exists in the library and the size of the group the persona represents.

In some cases, further analyses (e.g., principal component analysis (PCA), RapidMiner) determine how personas interact with one another. In these cases, personas are grouped with other personas that have commonalities (Blomquist \& Arvola, 2002; Hellstrom \& Eriksson, 2013; Leary \& Allen, 2011). For example, two personas may have a common connection of collaboration, but collaborate in different ways. The connection of collaboration would place them in the same group, but the way they collaborate would identify them as different personas. 


\begin{abstract}
Aims
This effort seeks to identify evidence about the universality of academic library personas. Zaugg et al. (2016) identified 10 personas at Brigham Young University (BYU) library. Researchers also used PCA to organize the personas into four groups with common use patterns. The three personas Focuser, Islander, an Outsider were identified as being task-oriented personas but each has a different motivation for interacting with the library. The Collaborator and Side-Kicks personas are focused on collaborating in the library, but in different ways. The social personas of Socializer, Chillaxer and Explorer are similar in that they each came to the library to socialize but have a different way of socializing. And the last two personas, the In-N-Outer and Pirate are in the tool persona group and come to the library mainly to use library tools. A more detailed description of these 10 personas is provided in Appendix A. Initially, it was thought that the personas were unique to BYU's library. Following discussions with colleagues at the University of Utah (UU), the researchers questioned the uniqueness of institutional personas. With this new insight in mind, this study sought to determine if personas are unique to an institution or whether they are more universal. Therefore, this research seeks to answer two questions: (1) In what ways are personas similar in two academic libraries? (2) In what ways are personas different in two academic libraries?
\end{abstract}

\title{
Library Descriptions
}

As BYU and the UU libraries have common and unique features, a brief description of each library is included below.

\section{BYU Library}

The BYU Library occupies a central location on the BYU campus. It serves approximately 33,000 faculty, staff, and students across 13 colleges. It hosts approximately six million items across six floors in an area of about 665,000 square feet $(60,850$ square meters). During prime semesters (fall and winter), it serves upwards of 15,000 patrons each day.

\section{UU Library}

The J. Willard Marriott Library is the main campus library on the UU campus and contributes to serving over 35,500 students and faculty. The library has approximately 521,000 square feet and supports faculty and students across 17 colleges. The library holds over three and a half million volumes, and has approximately 10,000 patrons visit each day.

\section{Methods}

This study is an extension of previous research identifying the 10 academic library personas (Zaugg, et al., 2016), and is focused on persona validation (Mulder \& Yaar, 2007). One change was made in this validation effort that differed from the previous research conducted by Zaugg et al. (2016). Previously, researchers provided undergraduate students one-sentence persona use statements and asked them to identify the one statement that best described their library behavior. During the first validation effort, it became apparent that students identified with multiple library personas. Therefore, in this study, that used an identical survey and use statements, students were asked to rate on a scale ranging from 1-7 $(1=$ not at all like me, $7=$ very much like me) to how closely the statement resembled their library use patterns (see Appendix B). 
Survey data was collected from students on each campus. The BYU Library sent out an online survey to a random sample of 1,500 undergraduate students and also randomly asked students walking by the library to complete the survey. The UU Library also randomly stopped students walking by the library and asked them to complete the survey but also collected paper surveys from patrons in the library. The researchers did not keep track of the number of students passing by or declining to take the survey so a final response rate is not known. The study was IRB approved at both universities.

Once collected, responses were summarized and then analyzed using three methods. The mean rating for each persona was used to group personas into high (4.00 or higher), Medium (3.00 3.99) and Low (Under 3.00) groupings. We also conducted a factorial ANOVA using the Least Square Difference to determine if there was a significant difference between the ratings given for each persona at each university. Following this we used Principle Components Analysis (PCA) and the RapidMiner analysis to examine personas that fit together. Simply put, both of these analysis tools examine how different personas, correlate with one another and predict the ways and the degree to which the personas are similar. The PCA analysis was part of a statistical analysis package. RapidMiner, a commercial data mining analytical program, is typically used to predict patterns and trends.

The mean rating and PCA analysis examined personas as a combined group and by institution. The RapidMiner analysis examined groupings where both institutions where rating from both institutions were at a 4 out of 7 or higher level. All analyses were used to triangulate and compare the personas found at each institution. As well they indicated the similarities and differences in persona groupings in the two libraries.

\section{Results}

A total of 903 students were surveyed $(\mathrm{BYU}=509, \mathrm{UU}=394)$, skewing the combined group slightly in BYU's favor. A between subjects factorial ANOVA was calculated comparing the ratings for each persona from each university. A significant main effect for personas was found $(\mathrm{F}(1,9)=178.83, \mathrm{p}<.0001)$. Using the Least Square Difference, we found a significant difference between the BYU and UU ratings for all but two personas (In-N-Outer and Outsider). All means, standard deviations and levels of significance are shown in Table 1. All ratings were within 1.4 points of each other, with UU having higher ratings on all but one persona (In-NOuter). The difference on seven of the 10 personas was less than one point. Considering the eight personas with a significant difference, five (Islander, Collaborator, Focuser, Side-Kick, and Pirate) had mean differences of .6 or less. While statistically significant, they are not considered a practical significant difference. The three personas that had both a significant and practical mean difference, were personas that were identified as personas that represent less than $7 \%$ of the entire library population (Zaugg et al., 2016).

To help answer the study questions of similarities and differences in the personas at the two academic libraries, the personas were sorted into groupings using three methods. The intent is to indicate the commonality of each grouping at each institution compared to both institutions. First, using the ratings for each institution and the combined ratings, all personas were placed into three groupings - High (ratings of 4.00 or higher), Medium (ratings of $3.00-3.99$ ), or Low (ratings less than 3.00). Table 2 shows these groupings by library and combined. 
Table 1

Mean Scores and Standard Deviations for Each Persona by School Affiliation.

\begin{tabular}{|c|c|c|c|c|c|c|c|}
\hline & \multicolumn{2}{|c|}{ Combined } & \multicolumn{2}{|c|}{ BYU } & \multicolumn{2}{|c|}{ UU } & BYU/UU \\
\hline & Mean & $\mathrm{SD}$ & Mean & SD & Mean & $\mathrm{SD}$ & Significance \\
\hline Islander & 4.7 & 1.96 & 4.5 & 1.99 & 5.0 & 1.90 & $\mathrm{P}<.0002$ \\
\hline Collaborator & 4.3 & 1.87 & 4.0 & 1.77 & 4.6 & 1.96 & $\mathrm{P}<.0001$ \\
\hline Focuser & 4.3 & 1.82 & 4.1 & 1.85 & 4.6 & 1.75 & $\mathrm{P}<.0003$ \\
\hline Side-Kick & 4.1 & 1.90 & 3.9 & 1.88 & 4.4 & 1.89 & $\mathrm{P}<.0001$ \\
\hline In-N-Outer & 3.8 & 1.95 & 3.8 & 1.90 & 3.7 & 2.01 & $P<.1151$ \\
\hline Pirate & 3.5 & 2.10 & 3.2 & 2.04 & 3.8 & 2.13 & $\mathrm{P}<.0001$ \\
\hline Explorer & 3.1 & 1.75 & 2.6 & 1.47 & 3.7 & 1.84 & $\mathrm{P}<.0001$ \\
\hline Chillaxer & 2.7 & 1.87 & 2.2 & 1.59 & 3.4 & 2.01 & $\mathrm{P}<.0001$ \\
\hline Socializer & 2.7 & 1.85 & 2.1 & 1.47 & 3.5 & 1.99 & $\mathrm{P}<.0001$ \\
\hline Outsider & 2.2 & 1.65 & 2.2 & 1.62 & 2.3 & 1.69 & $P<.3464$ \\
\hline
\end{tabular}

Mean ratings are out of a possible $7 . \mathrm{SD}=$ standard deviation. Shading indicates persona grouping by rating. Boldface indicates personas ratings that are not significantly higher.

Table 2

Persona Groupings for the Combined, BYU and UU Campuses sorted by mean rating.

\begin{tabular}{cccc} 
Grouping & Combined & BYU & UU \\
\hline & Islander & Islander & Islander \\
High (4 or higher) & Collaborator (t) & Collaborator & Collaborator (t) \\
& Focuser (t) & Focuser & Focuser (t) \\
& Side-Kick & & Side-Kick \\
& & & \\
Medium (3-3.99) & In-N-Outer & Side-Kick & Pirate \\
& Pirate & In-N-Outer & In-N-Outer (t) \\
& Explorer & Pirate & Explorer (t) \\
& & & Socializer \\
& & & Chillaxer \\
& Socializer (t) & Explorer & \\
Low (Less than 3) & Chillaxer (t) & Chillaxer (t) & Outsider \\
& Outsider & Socializer & \\
\hline
\end{tabular}

Mean ratings are out of a possible 7. (t) indicates a tie in the ratings.

Second, using PCA analysis and the combined, BYU, and UU ratings, we divided the 10 personas into three groupings (see Table 3). Unlike the groupings in Table 2, these do not indicate a hierarchy, but merely describe one way that the persona ratings correlate with one another to show similar use patterns. 
Table 3

Persona Groupings for the Combined, BYU and UU campuses using PCA.

\begin{tabular}{cccc} 
Grouping & Combined & BYU & UU \\
\hline \multirow{4}{*}{1} & $\begin{array}{c}\text { Focuser } \\
\text { Islander } \\
\text { Outsider^ }\end{array}$ & $\begin{array}{c}\text { Focuser } \\
\text { Islander } \\
\text { Outsider^ }\end{array}$ & $\begin{array}{c}\text { Explorer } \\
\text { Focuser } \\
\text { Pirate } \\
\text { In-N-Outer }\end{array}$ \\
& In-N-Outer & In-N-Outer & Islander \\
& Pirate & Pirate & Outsider \\
& & & \\
& Chillaxer & Chillaxer & \\
& Explorer & Explorer & Chillaxer \\
& Collaborator & Collaborator & Collaborator \\
& Side-Kick & Side-Kick & Side-Kick \\
& Socializer & Socializer & Socializer \\
\hline
\end{tabular}

Note. ${ }^{\wedge}$ Correlates negatively to other personas in group.

Finally, using RapidMiner analysis and paired persona ratings, we identified three groupings for the 10 personas. Similar to Table 2, these pairings indicate a hierarchy. Personas for patrons at both libraries were rated at the indicated level to be included in the grouping. Similar to Table 3 , Table 4 indicates hierarchal groupings where persona ratings for both BYU and UU were both in the defined level. For example, to be placed in the High rank the person for both institutions had to be at a rating level of 4 or higher. To be placed in the Medium groupings, both schools needed to have ratings between 3.00 and 3.99. Table 4 shows three potential groupings based on this hierarchal ranking.

Table 4

Groupings of personas for both BYU and UU sorted by high, medium, and low pairings.

\begin{tabular}{cccc} 
Rank & Grouping 1 & Grouping 2 & Grouping 3 \\
\hline High & Focuser & Focuser & Collaborator \\
(4 or higher) & Islander & Islander & Focuser \\
& Side-Kick & & Islander \\
& & & Side-Kick \\
& & & \\
Medium & Collaborator & Collaborator & Explorer \\
$(3.00-3.99)$ & In-N-Outer & Explorer & In-N-Outer \\
& & Side-Kick & Pirate \\
& & & \\
Low & Chillaxer & Chillaxer & Chillaxer \\
(Less than 3) & Explorer & In-N-Outer & Outsider \\
& Pirate & Outsider & Socializer \\
& Outsider & Pirate & \\
& Socializer & Socializer & \\
\hline
\end{tabular}


These three configurations were examined to determine similarities and differences between the libraries at each of the two institutions.

\section{Discussion}

Since patrons often identify with several personas and switch personas to meet their specific needs, examining personas requires a holistic approach. Taking a holistic approach that examines the persona groupings using three different analyses to determine similarities and differences in personas and how they interact with each other and at each library. It also prevents patron stereotyping by examining the interplay of patron personas as they navigate the library space and services.

\section{Similarities}

There is evidence to indicate that the personas identified in one academic library are present in the other. First, as mentioned earlier, all self-identified patron ratings for each persona are within 1.4 points or less with one another. Half of the personas had ratings that were within 0.6 points of each other. This similar ranking provides the first indication that personas found in one academic library are also found in the other. Most of the UU personas were rated higher than the BYU personas and all but two were significantly higher. This difference is attributed to the manner in which students were surveyed. The UU only collected response near or in the library. BYU emailed surveys to a sample of the entire student population, including those who do not or rarely come to the physical library. This finding accounts for the significantly higher UU ratings. However, the significantly higher ratings do not discount the finding that the specific persona ratings are extremely close. This finding lends support that the universality of personas.

Second, we were aware that some personas gravitate towards each other. While the groupings of personas were determined using different methods, several personas consistently paired in the same grouping, often with other personas. Our analysis placed personas into nine potential groupings. Eight of the ten personas were consistently paired together in seven or more of these groupings (see Table 5).

Table 5

Pairings of personas in total groupings.

\begin{tabular}{lc}
\multicolumn{1}{c}{ Persona Pairing } & $\begin{array}{c}\text { Number of } \\
\text { Groupings }\end{array}$ \\
\hline Chillaxer/Socializer & 9 \\
Focuser/Islander & 8 \\
In-N-Outer/Pirate & 8 \\
Collaborator/Sidekick & 7 \\
\hline
\end{tabular}

The consistency and repetition of pairings across the analysis methods, lends support that the personas not only exist at each campus, but that they function in similar ways. It should be noted that, while persona pairing are often common, it does not indicate the impact of the persona. For example, in an initial study (Zaugg et al. 2016), only 5\% of library patrons identified Chillaxers or Socializers as one of their personas. Focusers and Islanders had almost 10 times the number of 
patrons identifying with them. However, that the personas pair together provides evidence of similar use patterns in the library.

Two personas, Outsiders and Explorers, did not pair with other personas at a high rate, but did at a moderate rate. For example, both Outsiders and Explorers were separately paired with Socializers in five of the potential nine groupings. An examination of the Outsider persona indicates an additional unique pattern. By definition Outsiders are those patrons who do not typically come to the physical library to use the physical library resources. As a result they are placed in the lowest grouping for six groupings. Using the PCA, Outsiders correlated in a strong negative manner with personas with a strong positive association with the physical library, namely Focusers and Islanders. These findings, combined with the previous discussion, lend support that the 10 personas identified in one academic library are also found in the other and function in a similar manner.

\section{Differences}

The differences between the library personas focuses differences at the libraries. While personas are more or less constant, how they group together largely depends on the spaces offered at the specific library. BYU is set up to provide academic services (printers, interlibrary loan, reserve pick up) close to each library entrance. It is geared to have In-N-Outers come in and use popular services and leave.

BYU only has vending machines in a limited Food Friendly zone. UU has a café with booths nearby. The UU set up facilitates collaboration near the café especially with the Socializers and Chillaxers. UU also has a maker-space. this helps to explain the first grouping in Table 3 where Explorers, Pirates, and In-N-Outers match up with Focusers to create and explore options at this space. BYU does not have a Maker-Space.

BYU also has more computers for student access than UU does (684 vs 236). This explains the In-N-Outer/Pirate grouping at BYU. Students commonly come in use the libraries computers and leave. Furthermore, UU has unique collections (e.g., games for Entertainment Arts and Engineering program or diagnostic tools for dentistry students) that explains the Islander/Outsider grouping for the UU.

Each of these differences illustrate that while personas are common between the two academic libraries, they group differently based on the amenities offered at each library. It would be of interest to determine if one library added resources it currently does on have, if the groupings would shift. For example, if BYU added a cafeteria would it see similar groupings that the UU has around its cafeteria? Similarly, if UU added more computers for students to use, would it see a similar groups change to what BYU currently has?

\section{Limitations}

Several limitations need to be noted for this study. First, the study only involved two academic libraries, quite similar in nature. They serve comparable student bodies and faculties. They are of similar size and have a similar prominence at their respective universities. It would be of value to determine if similar persona patterns exist and could be validated at universities that differed in size, cultural make-up, and location. 
Second, some university libraries are broken into several, somewhat equal branches. Both of these libraries were the dominant library at their institution. It would be of interest to determine if these persona and group patterns existed in institutions with multiple and equal libraries.

Data collection may have also affected results. BYU used online and in-person data collection for their results. UU used a combination of in-person and paper-based data collection methods due to a lack of technology tool access. While UU data collection was in or near the library, BYU's data collection had a large sample that was not near the library. We surmise that more of the BYU respondents do not use the physical library than did the UU respondents, because of the proximity of data collection.

Looking at the persona data at different institutions can help identify unique library contexts that might drive new specific library initiatives or affirm how current initiatives are driving library use. Persona data can be used to help create new local surveys, which is important for finding out more about the local library culture, uncovering the contexts of library use, or building on library strengths (Hiller, 2001).

Third, more BYU respondents were in the Outsider category. Surveys at the UU were administered in or near the entrance to the library. Collecting data online at the UU would, most likely, result in a higher rate of Outsider personas. Finally, it would be good to increase the total responses for both institutions. This initiative includes not just getting more students to respond to the survey, but to have comparable numbers of respondents at each institution.

\section{Conclusion}

How do these findings influence the ways the libraries operate and interact with patrons? There is evidence that personas are universal. Those persons identified at BYU were also present at the UU library and could form the foundation of library service. The personas enable the librarians to see patrons through different lenses. For example, instead of seeing students studying, one begins to see Focusers, Side-Kicks, and Collaborators.

How the personas interact with each other can help librarians plan for or adjust spaces and services to meet patrons' needs. Personas and their groups help library staff to make the best decisions for changing or improving library spaces (Creaser, 2006). They help to provide a vision into the future of how libraries will be used and what library purposes will be.

Understanding personas is to better understand the nature of how students use libraries. Changes in the way people interact necessitate changes in the way librarians interact with patrons. It allows the librarian to see how the library fits into their patrons' lives and not force the patrons to fit into the life of the library. It is also important to consider the conceptions and training of library support staff for the newly emerging library learning environments (Fisher, Hallam, \& Partridge, 2005; Weaver, 2006). 


\section{References}

Al-Shboul, M. K., \& Abrizah, A. (2014), "Information needs: Developing personas of humanities scholars", The Journal of Academic Librarianship, Vol. 40 No. 5, pp. 500-509.

Bilandzic, M., \& Foth, M. (2013), "Libraries as coworking spaces”, Library Hi Tech, Vol. 31 No. 2, pp. 254-273.

Blomquist, A., \& Arvola, M. (2002), "Personas in action: Ethnography of an interaction design team", NordiCHI, pp. 19-23.

Creaser, C. (2006), "User surveys in academic libraries", New Review of Academic Librarianship, Vol. 12 No.1, pp. 1-15.

Cunningham, H. (2005), "Designing a website for one imaginary persona that reflects the needs of the many", Computers in Libraries, Vol. 25 No. 9, pp. 15-19.

Fisher, B., Hallam, G., \& Partridge, H. (2005), "Different approaches: Common conclusions. The skills debate of the twenty-first century", New Review of Academic Librarianship, Vol. 11 No. 1, pp. 13-29.

Fourie, I., \& Fourie, H. (2014), "Targeting users in information provision-more than researchers, students and professionals" Library Hi Tech, Vol. 32, No. 1, pp. 164-172.

Guenther, K. (2006). "Developing personas to understand user needs”, Online, Vol. 30 No. 5, pp. 49 51.

Hellstrom, A., \& Eriksson, H. (2013), “Among fumblers, talkers, mappers and organisers: Four applications of process orientation”, Total Quality Management, Vol. 24 No. 6, pp. 733-751.

Hiller, S. (2001), "Assessing user needs, satisfaction, and library performance at the University of Washington Libraries", Library Trends, Vol. 49 No. 4, pp. 605-625.

Idoughi, D., Seffah, A., \& Kolski, C. (2012), "Adding user experience into the interactive service design loop: A persona-based approach", Behavior \& Information Technology, Vol. 31 No. 3, pp. 287-303.

Leary, M. R., \& Allen, A. B. (2011), "Self-presentational persona: Simultaneous management of multiple impressions", Journal of Personality and Social Psychology, Vol. 101 No. 5, pp. 10331049 .

Mckay, L. (2010), "Adding the persona touch: With an eye on the user experience, some brands are inviting imaginary friends to the party", CRM Magazine, Vol. 14 No. 2, pp. 19-20.

Mulder, S., \& Yaar, Z. (2007), “Approaches to creating personas”, In S. Mulder (Ed.), The user is always right: A practical guide to creating and using personas for the web. Berkeley, CA: New Riders, pp. 33-54.

Olsen, G. (2004), "Making personas more powerful: Details to drive strategic and tactical design", Boxes and Arrows. Available at: http://boxesandarrows.com/making-personas-more-powerfuldetails-to-drive-strategic-and-tactical-design (accessed 9 February 2017). 
Pruitt, J., \& Grudin, J. (2003), "Personas: Practice and theory", Proceedings of the 2003 Conference on Designing for User Experience, San Francisco, CA, pp. 1-15.

Roberts, S., \& Weaver, M. (2006), "Spaces for learners and learning: Evaluating the impact of technology-rich learning spaces", New Review of Academic Librarianship, Vol. 12 No. 2, pp. 95-107.

Tempelman-Kluit, N., \& Pearce, A. (2014), "Invoking the user from data to design", College \& Research Libraries, Vol. 75 No. 5, pp. 616-640.

Weaver, M. (2006), "Exploring conceptions of learning and teaching through the creation of flexible learning spaces: The learning gateway - a case study", New Review of Academic Librarianship, Vol. 12 No. 2, pp. 109-125.

Zaugg, H., Rackham, S., Davis, M., Bleggi, J., Grout, A., Boehme, A., Carter, C., Brooks, C., McOmber, C., Douglas, L., Valentine, J., Stucki, S., Meacham, G., Clark, B., Coles, E., Dastrup, B., Miligan, R., and Whit, J. (2016), "Identification and development of patron personas for an academic library", Performance Measurement and Metrics, Vol. 17 No. 2, pp. 124-133. 


\section{Appendix A}

\section{Brief Descriptions of Undergraduate Library Personas}

\begin{tabular}{|c|c|c|c|}
\hline & Name & Description & Quotes \\
\hline \multirow{3}{*}{$\underset{\frac{\pi}{\pi}}{\frac{y}{\pi}}$} & Focuser & $\begin{array}{l}\text { Motivated by achievement (straight A } \\
\text { students), he/she is a personal studier who } \\
\text { equate the library with no distractions and } \\
\text { productivity. }\end{array}$ & $\begin{array}{l}\text { When I'm in the library, I feel like I'm more } \\
\text { effective, even if that's not true. My mind knows } \\
\text { I'm here to study, whereas if I'm at my house, I } \\
\text { don't study. My mind associates studying with the } \\
\text { library. }\end{array}$ \\
\hline & Islander & $\begin{array}{l}\text { Motivated by having a personal, quiet space to } \\
\text { enjoy the peace and quiet of the library, he/she } \\
\text { may be found at any time of the day reading } \\
\text { personal books, writing, drawing, thinking, or } \\
\text { even working on homework. }\end{array}$ & $\begin{array}{l}\text { I love that there's classical music playing } \\
\text { because it helps me study and relax. I feel like it } \\
\text { is my main area of the library. }\end{array}$ \\
\hline & Outsider & $\begin{array}{l}\text { He/She interacts with the library's services } \\
\text { through its website or databases and is } \\
\text { unfamiliar with the library and/or finds it } \\
\text { intimidating. This persona changes into other } \\
\text { personas as the patron becomes more familiar } \\
\text { with the library. }\end{array}$ & $\begin{array}{l}\text { You can find your own spot where no one can } \\
\text { bother you. }\end{array}$ \\
\hline \multirow[t]{2}{*}{ 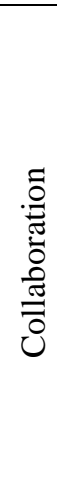 } & Collaborator & $\begin{array}{l}\text { Motivated by getting good grades, he/she } \\
\text { comes to collaborate with others for a specific } \\
\text { class project or study opportunity. Contains } 2 \\
\text { subgroups: } \\
\text { - Voluntarily forms a group to study. } \\
\text { - Involuntarily put in a group to complete a } \\
\text { class project. }\end{array}$ & $\begin{array}{l}\text { I use online resources three, four, five times a } \\
\text { week. For my major, the databases are the best } \\
\text { place. I read a lot of journal articles. So the } \\
\text { databases are the best places to access a variety } \\
\text { of articles across a spectrum. }\end{array}$ \\
\hline & Side-Kicks & $\begin{array}{l}\text { Motivated by studying with a friend but not } \\
\text { collaborating. He/She will sit with a friend but } \\
\text { study separate things. }\end{array}$ & $\begin{array}{l}\text { It seems big and imposing at times. It's } \\
\text { associated with intense studying, which brings a } \\
\text { lot of stress and anxiety to some people. }\end{array}$ \\
\hline \multirow{3}{*}{$\begin{array}{l}\cdot \bar{T} \\
0 \\
0 \\
\infty\end{array}$} & Socializer & $\begin{array}{l}\text { Motivated by the library's socialization } \\
\text { opportunities rather than its study opportunities, } \\
\text { he/she doesn't go to the library to study but to } \\
\text { socialize and meet people. He/She likes the No- } \\
\text { Shhh and Snack Zones. }\end{array}$ & $\begin{array}{l}\text { I do use group rooms a lot. I have had a lot of } \\
\text { group projects, or just study groups, so we'll } \\
\text { reserve a group study room. Group rooms with } \\
\text { TVs and computers are helpful. }\end{array}$ \\
\hline & Chillaxer & $\begin{array}{l}\text { Motivated by enjoying the atmosphere of the } \\
\text { library and by what they are doing, he/she will } \\
\text { break from studying to sleep, read a } \\
\text { recreational book, watch YouTube, play video } \\
\text { games, etc. }\end{array}$ & $\begin{array}{l}\text { Sometimes I use the study rooms for a group } \\
\text { project. Study rooms are helpful for projects. You } \\
\text { can't talk outside of the rooms. }\end{array}$ \\
\hline & Explorer & $\begin{array}{l}\text { Motivated to come to the library to explore or } \\
\text { discover, he/she uses its resources for things } \\
\text { above and beyond school requirements. }\end{array}$ & $\begin{array}{l}\text { Usually the same amount of work gets done when } \\
\text { I'm with a roommate. They just help me not be so } \\
\text { lonely. }\end{array}$ \\
\hline
\end{tabular}




\begin{tabular}{|c|c|l|l|}
\hline \multirow{2}{*}{\begin{tabular}{c} 
In-N-Outer \\
\cline { 2 - 4 }
\end{tabular}} & $\begin{array}{l}\text { Motivated to quickly use a library service and } \\
\text { then leave, he/she checks out a book, prints a } \\
\text { paper, or uses the atrium as a hallway between } \\
\text { destinations. }\end{array}$ & $\begin{array}{l}\text { I've tried to get dates on the fourth floor before. } \\
\text { I've had about a 50/50 success rate. I've gone to } \\
\text { flirt before. }\end{array}$ \\
\cline { 2 - 4 } Pirate & $\begin{array}{l}\text { Motivated to use library computers for } \\
\text { homework and social activities out of } \\
\text { convenience, they do not own or do not want to } \\
\text { bring their own computer. }\end{array}$ & $\begin{array}{l}\text { I come every day because I have class from 10- } \\
\text { 11, then my next one is at 12. So I come in } \\
\text { between. [I use] online stuff, I use the chairs, and } \\
\text { [I use] the Wifi. }\end{array}$ \\
\hline
\end{tabular}




\section{Appendix B: Validation Survey}

\section{Introduction}

This research study is being conducted by Holt Zaugg, Assessment Librarian at Brigham Young University (BYU) and Donna Ziegenfuss, Interim Head of Grad and Undergrad Services at the University of Utah (UU) to determine undergraduate use patterns at the Harold B. Lee Library (HBLL) at BYU and the Marriott Library at UU. You were invited to participate because you are an undergraduate student.

Procedures

If you agree to participate in this research study, the following will occur:

- you will be asked to complete a short survey, for approximately 5 minutes about your experience with the respective library.

\section{Risks/Discomforts}

There are minimal risks as you are only asked to provide demographic information and answer a single question about your use of the library. Participants may withdraw from the survey without penalty.

\section{$\underline{\text { Benefits }}$}

There is no direct benefit to participants other than the opportunity for the respective libraries to use the information to improve services.

Confidentiality

Only the researchers will have access to the data collected. Any data collected will be destroyed one year after the completion and dissemination of study results.

Compensation

You will be given a mini chocolate bar as compensation for participation.

Participation

Participation in this research study is voluntary. You have the right to withdraw at any time or refuse to participate entirely without jeopardy to your class status, grade, or standing with the university.

Questions about the Research

If you have questions regarding this study, you may contact Holt Zaugg (holt_zaugg@byu.edu) at BYU or Donna Ziegenfuss (donna.ziegenfuss@utah.edu) for further information.

Questions about Your Rights as Research Participants

If you have questions regarding your rights as a research participant contact the respective university IRB Administrators at (801) 422-1461; A-285 ASB, Brigham Young University, Provo, UT 84602; irb@byu.edu.

Statement of Consent

I consent to participate in this study.

Yes No 
What is your gender?

Female Male

What is your current year of studies?

Year 1 Freshman

Year 2 Sophomore

Year 3 Junior

Year 4 Senior

Year 5+

With which college/school are you affiliated?

[Specified by university]

Please indicate the degree to which each statement applies to how you currently use the Lee Library (Marriott Library)? $1=$ Not at all like me. 7 = Very much like me.

1. I come to the library to explore and discover things above and beyond class assignments.

2. I use the library's computers and stuff so I don't have to lug my stuff around.

3. I want good grades so I collaborate with friends in the class or with an assigned group.

4. I come here to find friends, and visit and relax in the zones that allow visiting and food (No Shh and Snack Zone). Work can come later.

5. I am focused on getting an A so please be quiet and don't bother or distract me!

6. I come here to relax away from roommates and school. I may take a break to nap, read a fun book, watch a DVD, or play games.

7. I get things done when I am with a friend even though we are studying different things.

8. I am in a hurry. I need to get something or print a paper, and get out of here!

9. I have my personal spot that suits my needs and matches my personality, whether I am doing homework or taking a break.

10. Why do I need or would I want to go to the library? I either get everything I need on-line or do not want to go there.

[This question is only included if the last statement is selected.]

We are interested in learning more about your use patterns of library services outside of the library, would you be willing to participate in a focus group or an interview?

I am willing to participate in a focus group.

I am willing to participate in an interview.

I do not want to participate.

[These questions are only included if one or both of the first two choices in the previous question are selected.]

What is your name?

What is an email address we can contact you at?

End of Survey 